\title{
Picture quiz in haematology
}

\section{Senani Williams ${ }^{1}$}

Journal of the Ceylon College of Physicians, 2021, 52, 115-117

1. A 56-year-old woman who recently returned from India, presents with fever of 4 days. On admission she has a borderline pancytopenia with hemoglobin of $10 \mathrm{~g} / \mathrm{dL}, \mathrm{WBC} 4 \times 10^{9} / \mathrm{L}$, and platelets $120 \times 10^{\%} / \mathrm{L}$. Her blood picture is given below.

What is the most likely diagnosis?

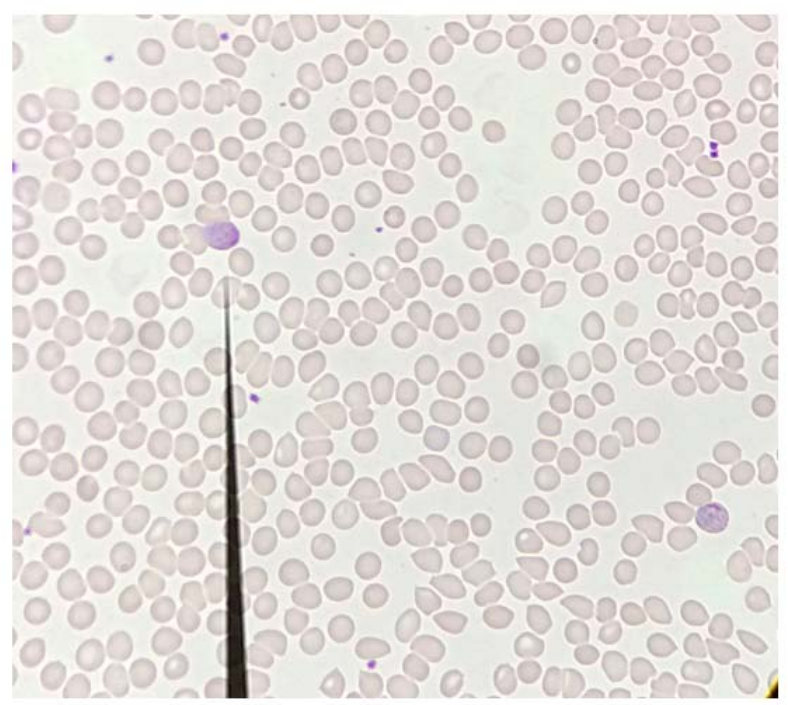

2. A 35-year-old man presents with mild tiredness. He complains of excessive tiredness during viral illnesses. His haemoglobin is $11.8 \mathrm{~g} / \mathrm{dL}$.

What is the salient red cell abnormality?

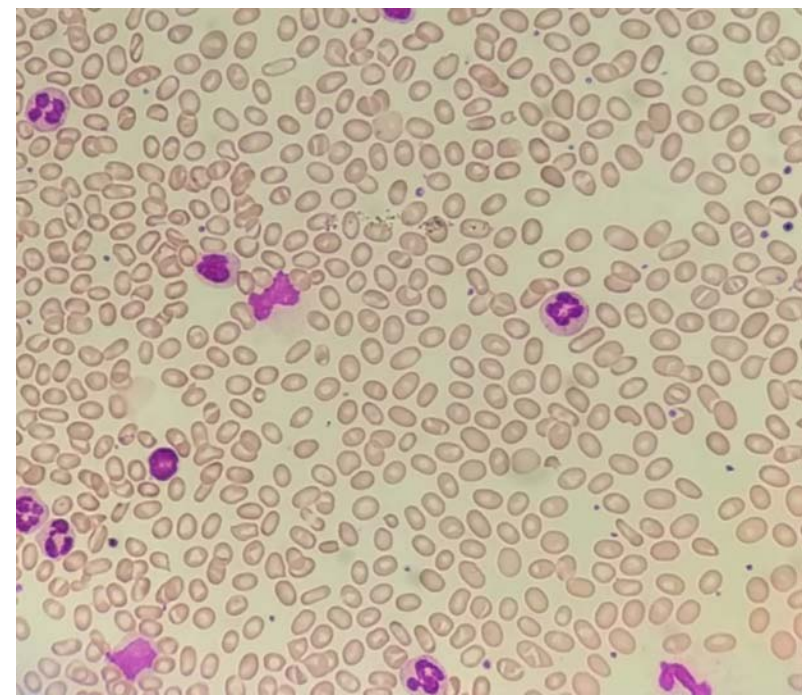

${ }^{1}$ Department of Pathology, Faculty of Medicine, University of Kelaniya, Sri Lanka.

Correspondence: E-mail: senaniw@kln.ac.lk

This is an open-access article distributed under the terms of the Creative Commons Attribution License, which permits unrestricted use, distribution, and reproduction in any medium, provided the original author and source are credited. 
3. A 25-year-old man has constitutional symptoms for one month with loss of weight, loss of appetite and body aches. On admission he complains of headache. On examination, cervical lymphadenopathy is noted. Investigations reveal, haemoglobin $7.0 \mathrm{~g} / \mathrm{dL}$, WBC $3.5 \times 10^{9} / \mathrm{L}$, Platelets $90 \times 10^{9} / \mathrm{L}$ and ESR of $90 \mathrm{~mm} 1^{\text {st }}$ hour.

What is the most likely diagnosis?

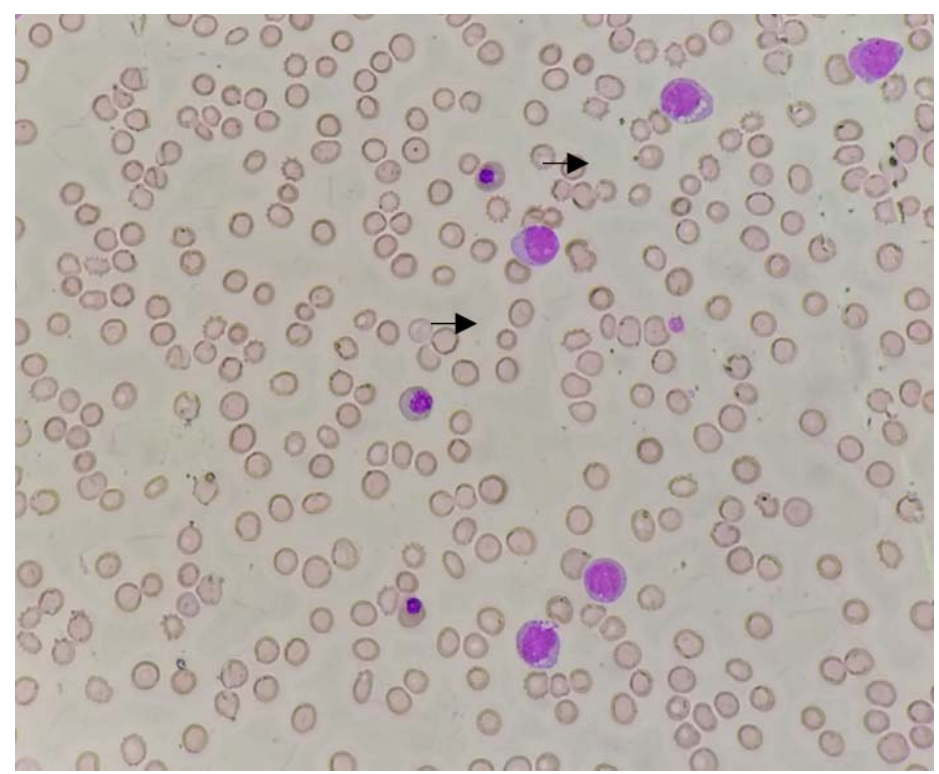

4. A 60-year-old man is brought to the emergency department in a confused state. He is severely pale and mildly icteric. His haemoglobin on admission is $3.0 \mathrm{~g} / \mathrm{dL}$ and his blood picture is given below.

What is the diagnosis?

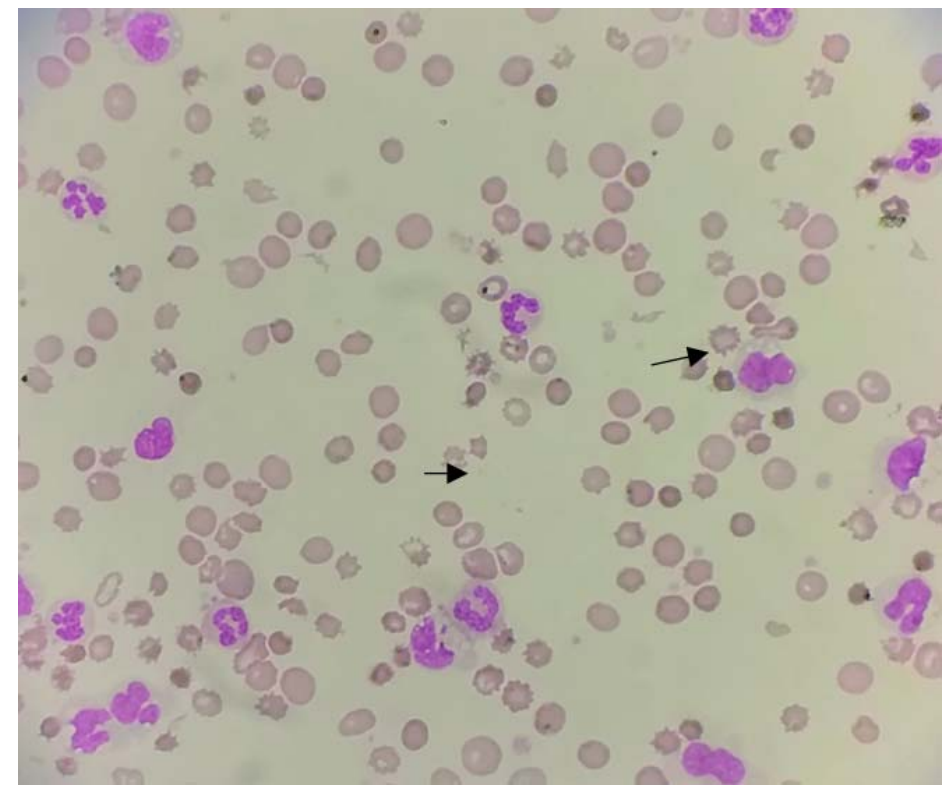


5. A 70-year-old man presents with constitutional symptoms and pancytopenia. His bone marrow aspiration was a dry tap. Photomicrographs of his trephine biopsy are provided.

What is the most likely diagnosis?
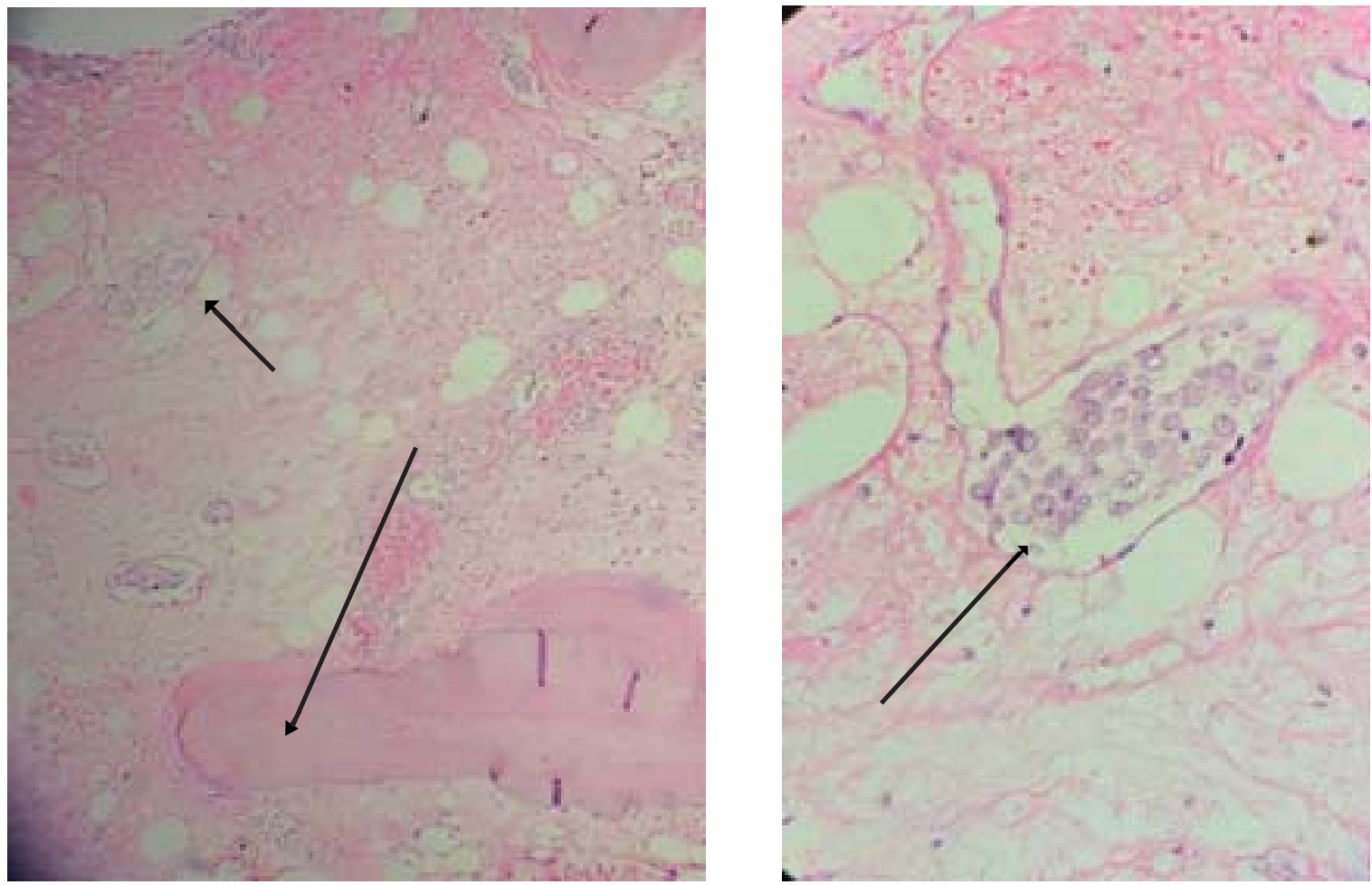

(Answers on page 118) 